\section{Alcoholics and the law}

As a lawyer acting exclusively for accused people in Saskatchewan, I note that the criminal justice system contains all the biases and negative attitudes toward people with addictions - particularly alcoholics - that are described in the CMAJ editorial by Stanbrook. ${ }^{1}$

An alcoholic who commits a crime (i.e., shoplifting mouthwash) to feed his or her habit will often be placed on probation with a "no alcohol" clause. When that clause is inevitably breached, the court is asked by the Crown to send the alcoholic to jail for violating a court order. Many judges will support the Crown's position. I have argued many times that, "telling an alcoholic to stop drinking is like telling someone with cancer to get better." Unfortunately, the court assumes that people make their own rational choices and that the alcoholic has chosen to drink. Thus, the alcoholic is legally responsible for ignoring the "no alcohol" clause in his or her probation order and must be sent to jail for deliberately ignoring the court's order.

In the debate over how to deal with alcoholics who are in conflict with the law, medical professionals would be a welcome addition. They could inject some medical knowledge into the debate, not allowing "misconceptions, stigma and ignorance" to triumph.

\section{Donald L. MacKinnon BA LLB}

Lawyer, North Battleford, Sask.

\section{Reference}

1. Stanbrook MB. Addiction is a disease: We must change our attitudes toward addicts. CMAJ 2012;184:155.

CMAJ 2012. DOI:10.1503/cmaj.112-2068

\section{Prognostic value of the ECG}

Although the first diagnosis of acute myocardial infarction by electrocardiogram (ECG) dates back to 1920, its prognostic value has enjoyed little attention in the era of "time is muscle." Instead, various time-based parameters and arithmetical formulas have dominated in both research and practice.
In our region in 2006, we started to organize "eye training" courses to help frontline acute cardiac care providers recognize early or subtle ECG changes in ST-segment elevation myocardial infarction (STEMI). This experience quickly led us to conclude that the initial ECG in STEMI actually had a higher potential to provide prognostic information than time-based parameters. Using a combination of 3 parameters (degree of ST elevation, preservation or degree of loss of $\mathrm{R}$ wave amplitude, and presence or absence of pathological Q waves), we can assess the status of myocardial injury, depolarization and permanent damage more objectively. Moreover, ECG does not rely on patient's recall, is widely available, inexpensive and easily repeatable.

Siha and coauthors show the longterm prognostic value of $\mathrm{Q}$ waves. ${ }^{1}$ Using serial ECG follow-up in our course material, we appreciated the value of a combination of 3 ECG parameters regarding timing and mode of therapy in acute STEMI. The message is "If time is myocardium, ECG must be the clock," which is equally applicable to urban and rural settings.

\section{Masis Perk MD}

Colchester Regional Hospital, Truro, NS

\section{Reference}

1. Siha H, Das D, Fu Y, et al. Baseline Q waves as a prognostic modulator in patients with ST-segment elevation: insights from the PLATO trial. CMAJ 2012;184:1135-42.

CMAJ 2012. DOI:10.1503/cmaj.112-2065

\section{Treating opioid addiction}

Nosyk and colleagues ${ }^{1}$ have analyzed data from the North American Opiate Medication Initiative (NAOMI) ${ }^{2}$ in an attempt to ascertain cost-effectiveness of diacetylmorphine versus methadone among those "refractory to treatment" (people in whom "standard" methadone maintenance has failed on average more than 3 times). For those meeting their inclusion criteria, the authors conclude, "... diacetylmorphine may be more effective and less costly than methadone maintenance."
The maximum duration of observation by NAOMI was 12 months, with no post-trial follow-up. Only 77 diacetylmorphine recipients $(67 \%)$ and 45 who received methadone $(41 \%)$ were retained on their assigned medication for even this limited period, but they were the basis for calculating and comparing "incremental cost-effectiveness ratios ... over 1-, 5-, 10-year and lifetime horizons." The study results indicated that over the course of a lifetime, people receiving methadone generated a societal cost of \$1.14 million compared with $\$ 1.10$ million generated by those receiving diacetylmorphine.

The most striking finding is barely mentioned in either the initial NAOMI publication $^{2}$ or in the article by Nosyk and colleagues. ${ }^{1}$ During the 1 -year course of the study, $15 \%$ (17) of methadone participants were, at their request, transferred from the "optimized" methadone treatment provided by NAOMI to "standard" methadone treatment in the community. Seventysix percent of those who voluntarily "switched" remained in treatment 12 months after initial enrolment. Even more remarkably, $21 \%$ (24) of those randomly assigned to diacetylmorphine left the trial to join "standard" maintenance programs (more than half did so voluntarily), and 23 of these 24 (96\%) were still receiving methadone maintenance in community facilities at 12 months. No explanation is offered for this unexpected retention in treatment that, as stated, had previously proven unsuccessful in the same setting an average of more than 3 times.

\section{Robert G. Newman MD MPH}

Director, Baron Edmond de Rothschild Chemical Dependency Institute of Beth Israel Medical Center, New York, NY

\section{References}

1. Nosyk D, Guh DP, Bansback NJ, et al. Cost-effectiveness of diacetylmorphine versus methadone for chronic opioid dependence refractory to treatment. CMAJ 2012;184:E317-28.

2. Oviedo-Jones E, Brissette S, Marsh DC, et al Diacetylmorphine versus methadone for the treatment of opioid addiction. N Engl J Med 2009; 361:777-86.

CMAJ 2012. DOI:10.1503/cmaj.112-2064 